\title{
SMR
}

\section{Comparison of the expression of human equilibrative nucleotide transporter 1 (hENT1) and ribonucleotide reductase subunit M1 (RRM1) genes in seven non-Hodgkin lymphoma cell lines}

\author{
H.B. Zhao ${ }^{1,2}$, X.F. Zhang ${ }^{1}$, F. Shi' ${ }^{2}$, M.Z. Zhang ${ }^{2}$ and W.L. Xue ${ }^{2}$ \\ ${ }^{1}$ Shangqiu Medical College, Shangqiu, China \\ ${ }^{2}$ The First Clinical Hospital of Zhengzhou University, Zhengzhou, China \\ Corresponding author: M.Z. Zhang \\ E-mail: zhangmingzhi_mz@163.com \\ Genet. Mol. Res. 15 (2): gmr.15028275 \\ Received December 15, 2015 \\ Accepted March 11, 2016 \\ Published May 6, 2016 \\ DOI http://dx.doi.org/10.4238/gmr.15028275
}

\begin{abstract}
We investigated the variability in the expression of human equilibrative nucleoside transporter 1 (hENT1) and ribonucleotide reductase subunit M1 (RRM1) in non-Hodgkin lymphoma cell lines. hENT1 and RRM1 mRNA expression levels in natural killer (NK) cells and seven non-Hodgkin lymphoma cell lines (YTS, SNK-6, Jeko-1, ly-1, Raji, Karpas, and Jurket) were studied using reverse-transcription quantitative real-time polymerase chain reaction (RT-qPCR) and the results were compared using the Student $t$-test. mRNA expression of hENT1 was detectable in YTS, SNK-6, Jeko-1, ly-1, Raji, Karpas, Jurket, and NK cells, which revealed variability in gene expression. There were significant differences in the mRNA expression values of hENT1 $(\mathrm{P}=0.021)$ and RRM1 $(\mathrm{P}=0.002)$ compared to those in NK cells. mRNA expression of both hENT1 and RRM1 was closely associated with non-Hodgkin lymphoma cell proliferation. Differential
\end{abstract}


expression analysis of hENT1 and RRM1 in non-Hodgkin lymphoma cell lines may provide novel drug leads for precision medicine.

Key words: Nucleotide transporters; Nucleoside analog; Cancer; Equilibrative nucleoside transporter proteins; Ribonucleotide reductase subunit M1

\section{INTRODUCTION}

Nucleosides, nucleotides, and nucleoside-derived analogue drugs participate in crucial processes both as nutrients and modulators of cellular homeostasis. They are hydrophilic molecules and cannot travel across cell membranes themselves. Thus, to fulfill their physiological roles and cytotoxic activities, nucleoside transporters (NTs) that mediate their uptake across cell plasma membranes are essential. The genes that encode NTs belong to solute carrier families 28 and 29 (SLC28 and SLC29), which encode human concentrative nucleoside transporters (hCNTs) and equilibrative nucleoside transporter proteins (hENTs), respectively. The human SLC29 family of proteins contains four members: hENT1, hENT2, hENT3, and hENT4. Recent research has revealed that in human solid tumors, the expression level of hENT1 predicts the response or resistance to gemcitabine-containing chemotherapy and survival, and it is a strong independent prognostic factor (Giovannetti et al., 2006; Farrell et al., 2009; Santini et al., 2011).

Ribonucleoside reductase subunit M1 (RRM1) carries a catalytic site and is a key enzyme for the formation of deoxyribonucleotides; nucleoside-derived analogue drugs as normal substrates may bind to the substrate-binding catalytic site of RRM1 and irreversibly inactivate the enzyme. It is involved in the cell proliferation, cell differentiation, invasion, and metastasis of cancer cells (Gautam et al., 2003). RRM1 is a cellular target for chemotherapeutic agents (Jordheim et al., 2011). Therefore, hENT1 and RRM1 expression may have prognostic significance as well as predictive value in human solid tumors. Non-Hodgkin lymphoma is a malignancy with a dismal prognosis, and chemotherapy efficacy varies among individuals. It is unknown whether differential expression of hENT1 and RRM1 can affect cellular functions and cytotoxic activities. Studies on the expression of hENT1 and RRM1 in non-Hodgkin lymphoma are rare. To evaluate their potential therapeutic applications or adverse effects, hENT1 and RRM1 expression levels in seven non-Hodgkin lymphoma cell lines were evaluated by reverse-transcription quantitative real-time polymerase chain reaction (RT-qPCR).

\section{MATERIAL AND METHODS}

\section{Cell culture}

Seven non-Hodgkin lymphoma cell lines (YTS, SNK-6, Jeko-1, ly-1, Raji, Karpas, and Jurket) and NK cells were suspended in culture medium comprising Roswell Park Memorial Institute (RPMI) 1640 medium (Gibco BRL, Life Technologies), 20\% fetal calf serum (Gibco BRL, Life Technologies), 2mM L-glutamine (Gibco BRL, Life Technologies), 100IU/mL penicillin, $100 \mu \mathrm{g} / \mathrm{mL}$ streptomycin, $0.125 \mu \mathrm{g} / \mathrm{mL}$ fungizone (Gibco BRL, Life Technologies), and $0.2 \mathrm{mg} / \mathrm{mL}$ gentamycin (Gibco BRL, Life Technologies). A minimum of $4 \times 10^{6}$ cells were lysed in Trizol reagent (Life Technologies). 


\section{RNA extraction and cDNA synthesis}

Total RNA was isolated from NK, YTS, SNK-6, Jeko-1, ly-1, Raji, Karpas, and Jurket cells with Trizol reagent, as recommended by the manufacturer (Life Technologies) and as previously described (Boudreau-Larivière et al., 2000). RNA was subjected to DNase treatment (Life Technologies) and subsequently stored at $-80^{\circ} \mathrm{C}$ until required. RNA samples were quantified using a Gene Quant II spectrophotometer (GE Healthcare). cDNA synthesis was performed according to the manufacturer protocol (Thermo Scientific RevertAid First Strand cDNA Synthesis Kit, USA). Briefly, following a denaturation step of $5 \mathrm{~min}$ at $65^{\circ} \mathrm{C}$, $1 \mu \mathrm{g}$ total RNA was reverse transcribed to single-stranded cDNA using a mix of $9 \mu \mathrm{L}$ RNase Free $\mathrm{dH}_{2} \mathrm{O}$ and $1 \mu \mathrm{L}$ oligo (dT) 18 primer. The reverse transcription reaction was performed in a total volume of $20 \mu \mathrm{L}$ containing $2 \mu \mathrm{L} 10 \mathrm{~mm}$ dNTP Mix, $1 \mu \mathrm{L}$ RevertAid M-MuLV RT $(200 \mathrm{U} / \mu \mathrm{L}), 1 \mu \mathrm{L}$ RiboLock RNase Inhibitor $(20 \mathrm{U} / \mu \mathrm{L})$, and $4 \mu \mathrm{L} 5 \mathrm{X}$ Reaction Buffer at $42^{\circ} \mathrm{C}$ for $60 \mathrm{~min}$ and $70^{\circ} \mathrm{C}$ for $5 \mathrm{~min}$, followed by a $4^{\circ} \mathrm{C}$ pause. The obtained cDNA was diluted to a final concentration of $8 \mathrm{ng} / \mu \mathrm{L}$. Samples were stored at $-80^{\circ} \mathrm{C}$.

\section{Reverse-transcription quantitative real-time PCR}

The mRNA expression levels of hENT1 and the endogenous housekeeping gene encoding glyceraldehyde-3-phosphate dehydrogenase (GAPDH) as a reference were quantified by RT-qPCR analysis (Taqman) using an Applied Biosystem 7500 Fast Real-Time PCR System (Thermo Fisher Scientific). Amplification of specific PCR products was detected with a One Step SYBR ${ }^{\circledR}$ PrimeScript ${ }^{\mathrm{TM}}$ RT-PCR Kit (Takara Biotechnology (Dalian) Co., Ltd., China). All primers and probe combinations were designed using Primer Premier 6.0 (Premier Biosoft, Canada) and purchased from Sangon (Sangon Biotech (Shanghai) Co., Ltd., China). The hENT1, RRM1, and GAPDH primers are listed in Table 1.

Table 1. Primer sequences.

\begin{tabular}{l|l|l}
\hline Name & Forward & Reverse \\
\hline hENT1 & 5'-TGC CTT CGG CTA CTT TAT CAC-3' & 5'-TTG GCT CCT CTC CTT TGC TA-3' \\
\hline RRM1 & 5'-CACCAGCAAAGATGAGGTTGC-3' & 5'-GGGGCGATGGCGTTTATTTG-3' \\
\hline GAPDH & 5'-CGG ATT TGG TCG TAT TGG G-3' & 5'-CTG GAA GAT GGT GAT GGG ATT-3' \\
\hline
\end{tabular}

According to the manufacturer protocol, RT-qPCR was performed in a total reaction volume of $50 \mu \mathrm{L}$ containing $25 \mu \mathrm{L} 2 \mathrm{X}$ UltraSYBR Mixture (with ROX), $1 \mu \mathrm{L} 10 \mu \mathrm{M}$ forward primer, $1 \mu \mathrm{L} 10 \mu \mathrm{M}$ reverse primer, $31 \mu \mathrm{L}$ RNase Free $\mathrm{dH}_{2} \mathrm{O}$, and $2 \mu \mathrm{L}$ cDNA as a template. Samples were pre-denatured at high temperature for $10 \mathrm{~min}\left(95^{\circ} \mathrm{C}\right)$ and amplified during 40 cycles of $15 \mathrm{~s}$ at $95^{\circ} \mathrm{C}$ and $60 \mathrm{~s}$ at $60^{\circ} \mathrm{C}$. The mRNA expression level for each target PCR relative to $G A P D H$ was calculated.

\section{Statistics}

Values are reported as means \pm SD. Data were analyzed using SPSS13.0 (SPSS, Inc., Chicago, IL, USA). The Student $t$-test was used for comparisons. Statistical significance was set at $\mathrm{P}<0.05$. 


\section{RESULTS}

\section{RRM1 gene expression in YTS, SNK-6, Jeko-1, ly-1, Raji, Karpas, and Jurket cells}

Figure 1 shows the variability of RRM1 gene expression observed in the seven nonHodgkin lymphoma cell lines and the NK cells subjected to transcription analysis. mRNA expression of hENT1 was detectable in all the samples. The analysis of YTS, SNK-6, Jeko-1, ly-1, Raji, Karpas, Jurket, and NK cells revealed variable gene expression, and the Student's $t$-test showed a significant difference $(\mathrm{P}=0.002<0.005)$ in the expression values for each gene compared with the NK cells.

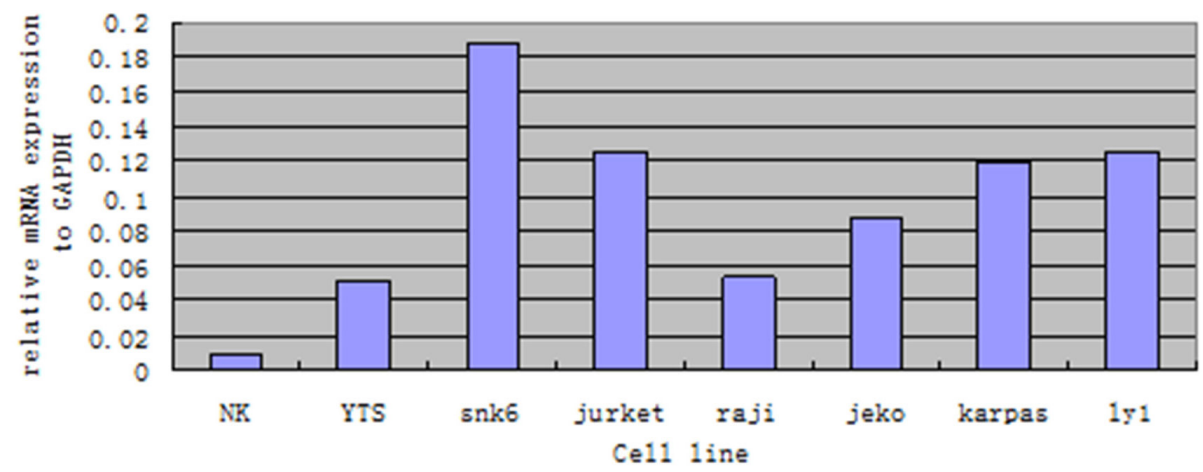

Figure 1. RRM1 gene expression in YTS, SNK-6, Jeko-1, ly-1, Raji, Karpas, and Jurket cells.

\section{hENT1 gene expression in YTS, SNK-6, Jeko-1, ly-1, Raji, Karpas, and Jurket cells}

Figure 2 shows the variability of hENT1 gene expression observed in seven nonHodgkin lymphoma cell lines and the NK cells subjected to transcription analysis. mRNA expression of hENT1 was detectable in all the samples. The analysis of YTS, SNK-6, Jeko-1, ly-1, Raji, Karpas, Jurket, and NK cells revealed variable gene expression, and the Student's $t$-test showed a significant difference $(\mathrm{P}=0.021<0.005)$ in the expression values for each gene compared with the NK cells.

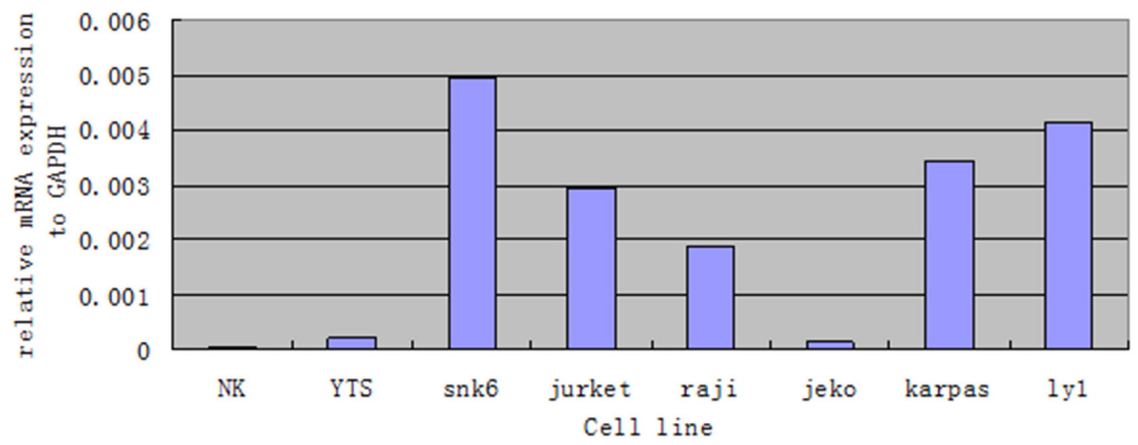

Figure 2. hENT1 gene expression in YTS, SNK-6, Jeko-1, ly-1, Raji, Karpas, and Jurket cells. 


\section{DISCUSSSION}

Precision medicine is gradually altering the traditional treatments of chemotherapy, and patient-specific data for each type of cancer is becoming essential. hENT1 can mediate the uptake of nucleoside and nucleoside-derived analog drugs, which impacts the efficacy of anticancer drugs. Today it is well known that hENT1 may have a prognostic role as well as predictive value in many types of solid tumors in patients treated with gemcitabine, and the differential expression of hENT1 can affect the cellular phenotype and cytotoxicity of anticancer drugs (Lee et al., 2014).

To gauge hENT1 expression in tumor cells, immunohistochemistry has been used in many solid tumor studies, but hENT1 gene expression in non-Hodgkin lymphoma cell lines is rarely mentioned. In this study, seven non-Hodgkin lymphoma cell lines (YTS, SNK-6, Jurket, Raji, Jeko-1, Karpas, and ly-1) and NK cells were cultured in vitro. The expression of hENT1 in these cell lines was observed by immunofluorescence microscopy, which revealed a high intensity of expression on the plasma membrane. mRNA expression of hENT1 was detectable in the all samples. The analysis of the YTS, SNK-6, Jeko-1, ly-1, Raji, Karpas, Jurket, and NK cells revealed variable gene expression, and showed a significant difference $(\mathrm{P}=0.021<$ 0.005 ) in the expression values for each gene compared with the NK cells.

RRM1, a key enzyme for the synthesis of deoxyribonucleotides, is involved in tumor and metastasis development, and has been associated with clinical features in solid tumor patients. In this study, the mRNA expression of RRM1 was detectable in the YTS, SNK-6, Jeko-1, ly-1, Raji, Karpas, Jurket, and NK cells. The analysis of all samples revealed gene expression variability, and showed a significant difference $(\mathrm{P}=0.002<0.005)$ in the expression values for each gene compared with the NK cells.

Our study revealed that there was greater variability in the gene expression of hENT1 and RRM1 in the non-Hodgkin lymphoma cell lines compared with the NK cells. Their variability was good, suggesting a possible relationship between cancer cell proliferation and gene expression of hENT1 and RRM1; this explained why the chemotherapy regimen had different results.

The mRNA expression changes of hENT1 were almost the same as for RRM1. These data demonstrate, for the first time, that the gene expression of hENT1 and RRM1 is relevant, and showed that non-Hodgkin lymphoma cell proliferation may require the synergistic effect of hENT1 and RRM1. Sasaki et al. (2014) reported high intratumoral hENT1 and RRM1 expression levels in $86(68 \%)$ and $67(53 \%)$ patients, but high hENT1 $(\mathrm{P}=0.044)$ and low RRM1 expression $(\mathrm{P}=0.009)$ were independently associated with prolonged disease-free survival (DFS).

In conclusion, both hENT1 and RRM1 gene expression levels were closely associated with non-Hodgkin lymphoma cell proliferation. Differential expression analysis of hENT1 and RRM1 in non-Hodgkin lymphoma cell lines may provide novel drug leads for precision medicine.

\section{Conflicts of interest}

The authors declare no conflict of interest.

\section{REFERENCES}

Boudreau-Larivière C, Chan RY, Wu J and Jasmin BJ (2000). Molecular mechanisms underlying the activity-linked alterations in acetylcholinesterase mRNAs in developing versus adult rat skeletal muscles. J. Neurochem. 74: 22502258. http://dx.doi.org/10.1046/j.1471-4159.2000.0742250.x 
Farrell JJ, Elsaleh H, Garcia M, Lai R, et al. (2009). Human equilibrative nucleoside transporter 1 levels predict response to gemcitabine in patients with pancreatic cancer. Gastroenterology 136: 187-195. http://dx.doi.org/10.1053/j. gastro.2008.09.067

Gautam A, Li ZR and Bepler G (2003). RRM1-induced metastasis suppression through PTEN-regulated pathways. Oncogene 22: 2135-2142.http://dx.doi.org/10.1038/sj.onc.1206232

Giovannetti E, Del Tacca M, Mey V, Funel N, et al. (2006). Transcription analysis of human equilibrative nucleoside transporter-1 predicts survival in pancreas cancer patients treated with gemcitabine. Cancer Res. 66: 3928-3935. http://dx.doi.org/10.1158/0008-5472.CAN-05-4203

Jordheim LP, Sève P, Trédan O and Dumontet C (2011). The ribonucleotide reductase large subunit (RRM1) as a predictive factor in patients with cancer. Lancet Oncol. 12: 693-702. http://dx.doi.org/10.1016/S1470-2045(10)70244-8

Lee Y, Koay EJ, Zhang W, Qin L, et al. (2014). Human equilibrative nucleoside transporter-1 knockdown tunes cellular mechanics through epithelial-mesenchymal transition in pancreatic cancer cells. PLoS One 9: e107973. http://dx.doi. org/10.1371/journal.pone. 0107973

Santini D, Schiavon G, Vincenzi B, Cass CE, et al. (2011). Human equilibrative nucleoside transporter 1 (hENT1) levels predict response to gemcitabine in patients with biliary tract cancer (BTC). Curr. Cancer Drug Targets 11: 123-129. http://dx.doi.org/10.2174/156800911793743600

Sasaki H, Murakami Y, Uemura K, Sudo T, et al. (2014). Concurrent analysis of human equilibrative nucleoside transporter 1 and ribonucleotide reductase subunit 1 expression increases predictive value for prognosis in cholangiocarcinoma patients treated with adjuvant gemcitabine-based chemotherapy. Br. J. Cancer 111: 1275-1284. http://dx.doi. org/10.1038/bjc.2014.399 